\title{
BAGAIMANA WARGA BINAAN DENGAN KASUS PENCABULAN ANAK MEMAKNAI VONISNYA? INTERPRETATIVE PHENOMENOLOGICAL ANALYSIS
}

\author{
Dian Veronika Sakti Kaloeti, Yohanis Franz La Kahija, Salma Salma
}

\author{
Fakultas Psikologi, Universitas Diponegoro, \\ Jl. Prof. Soedarto, SH, Kampus Undip Tembalang, Semarang, Indonesia 50275 \\ Pusat Pemberdayaan Keluarga, Fakultas Psikologi, Universitas Diponegoro \\ Jl. Prof. Soedarto, SH, Kampus Undip Tembalang, Semarang, Indonesia 50275
}

dvs.kaloeti@live.undip.ac.id

\begin{abstract}
Child molestation was a form of child exploitation which gets serious concern from Indonesian government. A number of literatures has been investigated on traumatic effect of child predatory among children. However, study which explored child molester's lived experience was still limited. This study aims to understand the lived experience of child molester after being sentenced. Three prisoners of Correctional Institution Kedungpane Semarang Indonesia were interviewed using semi-structured interview. Using interpretative phenomenological analysis, data were analyzed. Four superordinate themes emerged from analysis: (1) failure to resolve conflicts with victim's family, (2) disappointment of case disclosure, (3) attempt to escape severe punishment, and (4) effort to accept sentence. This result showed the need to find more effective strategy to help prisoners understand the effect of their behavior to children. Some suggestions to improve insight process amon g child molesters were also proposed.
\end{abstract}

Keywords: child molestation; prisoner; lived experience; interpretative phenomenological analys is

\begin{abstract}
Abstrak
Salah satu bentuk eks ploitasi anak-anak yang menjadi perhatian serius pemerintah adalah pencabulan anak. Sudah banyak literatur yang menyoroti dampak traumatis pencabulan pada anak di bawah umur. Bagaimanapun, masih sedikit literatur yang mengeksplorasi dunia pengalaman pelaku pencabulan. Penelitian ini bertujuan memahami bagaimana narapidana pencabulan anak di bawah umur memaknai vonis yang sedang dijalaninya di masa tahanan. Tiga narapidana yang menjadi partisipan dalam penelitian ini direkrut di Lembaga Pemasyarakatan Kedungpane Semarang untuk selanjutnya diwawancarai secara semi-terstruktur. Transkrip wawancara dianalisis secara kualitatif dengan menggunakan pendekatan analisis fenomenologis interpretatif (interpretative phenomenological analysis). Analisis data memunculkan empat tema superordinat, yaitu (1) kegagalan berdamai dengan keluarga korban, (2) kekecewaan pada keterungkapan kasus, (3) upaya luput dari hukuman berat, dan (4) upaya menerima vonis. Hasil penelitian ini menunjukkan perlunya menemukan upaya yang lebih efektif dalam membantu narapidana melihat dampak dari perbuatan mereka pada anak di bawah umur. Beberapa saran juga dikemukakan untuk membenahi proses penyadaran diri narapidana.
\end{abstract}

Kata kunci: pencabulan anak; warga binaan pemasyarakatan; makna vonis; interpretative phenomenological analysis

\section{PENDAHULUAN}

Sejak tahun 2014, Kementerian Pemberdayaan Perempuan dan Perlindungan Anak Republik Indonesia menyatakan bahwa Indonesia mengalami darurat kekerasan seksual pada anak. Pernyataan itu menunjukkan tingginya angka kekerasan seksual pada anak di Indonesia di tengah berbagai usaha pemerintah menurunkan angka kekerasan seksual pada anak. Tren itu masih cenderung fluktuatif dan belum menunjukkan penurunan yang signifikan (KPAI, 2018). Selain itu, laporan mengenai kasus kekerasan seksual pada anak rata-rata terjadi di sekolah dan lingkungan tempat tinggal korban di mana oknum guru, tetangga, 
bahkan teman sebaya adalah pelaku dari kekerasan tersebut. Walaupun terdapat penurunan yang drastis sejak tahun 2014 sampai saat ini, data yang terungkap sangat mungkin merupakan fenomena gunung es. Komnas Perlindungan Anak menemukan kecenderungan masyarakat untuk enggan melaporkan kasus-kasus tersebut karena dirasa sebagai aib atau kurangnya akses informasi mengenai pelaporan kasus tindak pidana kekerasan seksual pada anak (KPAI, 2018).

Angka kekerasan seksual pada anak yang tidak kunjung turun, walaupun berbagai usaha telah dilakukan pemerintah mengindikasikan belum optimalnya bentuk berbagai intervensi yang telah dilakukan. Memahami kondisi psikologis para predator seksual pada anak merupakan hal yang penting. Melalui pemahaman yang komprehensif mengenai dinamika psikologis para pelaku kejahatan seksual pada anak, pemerintah maupun pihak lain yang terkait dengan tanggung jawab penurunan angka kekerasan seksual ini mungkin akan dapat merumuskan hal yang lebih tepat sasaran dalam mengatasi masalah ini. Pemahaman ini selanjutnya dapat dikembangkan sebagai rumusan intervensi yang bersifat preventif maupun kuratif bagi para pelaku kekerasan seksual pada anak yang lebih tepat di samping dengan diberlakukannya berbagai usaha yang selama ini telah dijalankan.

Secara umum, terdapat dua jenis kejahatan seksual pada anak, yaitu pedophilic dan nonpedophilic child molester (Suchy, Whittaker, Strassberg, \& Eastvold, 2009). Perbedaan yang paling mendasar dari keduanya terletak dari usaha dalam memunculkan perilaku seksual. Pedophilic child molester biasanya memiliki ketertarikan serta dorongan seksual yang lebih kuat dibandingkan dengan nonpedophilic child molester. Sebagai konsekuensi, pedophilic child molester cenderung melakukan kekerasan seksual, mengulang perilaku tersebut sebagai cara memenuhi kebutuhan seksualnya. Di sisi lain, non-pedophilic child molester cenderung fokus kepada keterikatan dengan anak karena merasa kesulitan dalam membangun hubungan romantis dan seksual dengan orang dewasa (Cohen \& Galynker, 2009). Selanjutnya Schiffer dan Vonlaufen (2010) mendapati perbedaan fungsi eksekutif di antara kedua jenis child molester ini. Secara umum, Pedophilic child molester maupun nonpedophilic child molester memiliki kecenderungan disfungsi kognitif (cognitive dysfunction) yang ditandai dengan impulsivitas dalam pembuatan keputusan, fleksibilitas kognitif (cognitive flexibility), dan memori verbal, di mana fungsi-fungsi tersebut dimunculkan pula oleh disfungsi korteks orbitofrontal dan dorsolateral prefrontal. Lebih lanjut, penelitian ini menemukan bahwa pedophilic child molester memiliki kecenderungan fleksibilitas kognitif dan memori verbal yang lebih tinggi dibandingkan dengan nonpedophilic child molester, sehingga pelaku kekerasan seksual pada anak biasanya memiliki kemampuan yang baik untuk melakukan penetrasi sosial kepada anak-anak serta mudah diterima oleh banyak kalangan, seperti orang tua dan guru (Schiffer \& Vonlaufen, 2010). Lebih lanjut, laki-laki memiliki kecenderungan yang lebih tinggi untuk menjadi pedophilic child molester dibandingkan dengan perempuan. Hal ini disebabkan oleh dorongan seksual yang lebih tinggi pada laki-laki dan perempuan lebih fokus pada membangun relasi dengan anak-anak, memiliki rasa empati yang lebih besar, dan cenderung pada pemenuhan afeksi melalui aktivitas bersama anak-anak karena sulitnya membangun relasi dengan teman sebaya (van der Put, van Vugt, Stams, \& Hendriks, 2014).

UU No. 22 tahun 2002 tentang Perlindungan Anak memuat lamanya hukuman penjara bagi pelaku kekerasan seksual pada anak adalah minimal lima tahun penjara dan maksimal 15 tahun. Sejumlah penelitian mengungkapkan bahwa proses memasuki penjara dan khususnya bagi narapidana yang mengetahui bahwa masa tahanannya akan berlangsung lama, ditemui sejumlah emosi negatif yang mengiringi masuknya terpidana ke dalam 
penjara. Adapun dampak tersebut muncul dalam bentuk penyangkalan (denial), distres psikologis, kecemasan, depresi, gangguan kuantitas dan kualitas tidur, rasa malu, rasa bersalah, maupun perilaku kriminal lain dalam penjara, seperti bullying (Sinha, 2010; Tomar, 2013; Yi, Turney, \& Wildeman, 2016; Fazel, Hayes, Bartellas, Clerici, \& Trestman, 2016; Baćak, Andersen \& Schnittker 2018).

Penjatuhan pidana penjara menjadi sanksi yang dominan diambil dalam sistem peradilan di Indonesia. Lama atau tidaknya warga binaan menjalani kehidupan di dalam Lembaga Pemasyarakatan (Lapas) tergantung dari vonis yang diberikan oleh hakim. Leigey (2010) menyatakan bahwa individu yang baru saja menerima vonis harus berjuang dengan proses transisi di dalam penjara, mengalami perasaan marah dan balas dendam yang intens. Mereka yang mampu beradaptasi dengan baik mengalami gangguan kesehatan mental yang lebih rendah dibandingkan yang tidak mampu. Ginneken dan Hayes (2016) menegaskan bahwa warga binaan yang mampu menerima vonisnya akan berusaha berperilaku positif dengan harapan mendapatkan penilaian baik selama proses pembinaan di dalam Lapas.

Berdasarkan paparan di atas, pertanyaan utama yang akan diangkat adalah bagaimana warga binaan dengan kasus pencabulan pada anak memaknai vonisnya? Penelitian ini bertujuan untuk mengetahui dan memahami pengalaman warga binaan dengan kasus pencabulan anak memaknai vonisnya di dalam Lembaga Pemasyarakatan.

\section{METODE}

\section{Desain Penelitian}

Penelitian kualitatif ini menggunakan interpretative phenomenological analysis (IPA) untuk memahami pengalaman hidup narapidana yang sedang menjalani masa tahanan untuk kasus pencabulan anak. Sejauh ini, sudah banyak publikasi penelitian kualitatif dalam psikologi yang menggunakan pendekatan IPA (Brocki \& Wearden, 2006).
Secara

konseptual-teoretis,

IPA

dikembangkan dari gagasan-gagasan pokok dalam filsafat fenomenologis-interpretatif; sementara secara praktis-prosedural, IPA berkembang dalam psikologi sebelum penggunaannya menyebar ke disiplin-disiplin lain (La Kahija, 2017). Dalam filsafat fenomenologis, pengalaman langsung dipandang sebagai sumber primer dari ilmu pengetahuan sehingga penelitian fenomenologis diminta untuk kembali pada pengalaman langsung itu. Dalam IPA, pandangan fenomenologis itu diterapkan dengan cara memperlakukan semua partisipan sebagai pakar dalam bidang pengalaman hidupnya masing-masing (Brocki \& Wearden, 2006). Untuk penelitian ini, partisipan yang pengalaman hidupnya dieksplorasi adalah narapidana kasus pencabulan anak di lembaga pemasyarakatan Kedung Pane Semarang.

\section{Partisipan}

Narapidana dalam penelitian ini direkrut secara purposif dengan memerhatikan homogenitas pengalaman yang menjadi fenomena. Proses rekrutmen dilakukan dengan bantuan orang kunci (key person) yang adalah psikolog yang bertugas di Lembaga Pemasyarakatan Kedung Pane Semarang. Saat menyeleksi partisipan, peneliti berfokus pada narapidana yang menjalani hukuman untuk kasus pencabulan anak. Hasilnya, peneliti mendapatkan tiga partisipan dengan rentang usia antara 28 dan 48 tahun dan rentang vonis antara 7 dan 20 tahun. Seperti yang umum ditemui dalam penelitian fenomenologis, penentuan jumlah partisipan tidak bersandar pada strategi sampling, tetapi strategi kedalaman analisis (Giorgi, 2009). Oleh karena itu, jumlah sampel yang kecil bukan masalah sejauh analis is dilakukan secara rinci untuk mengungkap perbedaan dan kemiripan dalam jumlah sampel yang kecil itu (Matthews \& Ross, 2010).

\section{Pengumpulan Data}

Data atau informasi tentang pengalaman hidup partisipan didapatkan melalui 
wawancara semi-terstruktur. Peneliti mewawancarai partisipan dengan panduan wawancara yang berisi serangkaian pertanyaan non-direktif. Pertanyaan utama yang diajukan kepada partisipan adalah "Bisa ceritakan apa yang terjadi dalam hidup Anda sampai Anda berada di lembaga pemasyarakatan ini?" Pertanyaan-pertanyaan menyusul adalah pendalaman dari pertanyaan utama itu. Partisipan diberikan kesempatan yang luas untuk menceritakan pengalaman hidupnya. Bila ada jawaban yang perlu diperjelas, peneliti meminta klarifikasi. Saat bertanya, peneliti sebagai pewawancara menjaga diri agar memerhatikan epochē (netralitas) dalam mengajukan pertanyaan. Di akhir wawancara, peneliti memastikan tidak ada lagi yang perlu ditambahkan oleh partisipan. Proses wawancara direkam dan hasilnya ditranskripsikan secara verbatim. Tujuan utama dalam wawancara ini adalah mendapatkan informasi yang kaya untuk dianalisis. Ini sejalan dengan pandangan fenomenologis tentang pentingnya analisis yang detail tentang pengalaman partisipan sebagai orang yang mengalami langsung suatu peristiwa atau fenomena (La Kahija, 2017).

\section{Prosedur}

Wawancara dijalankan dalam ruang khusus yang disediakan oleh petugas di lembaga Pemasyarakatan Kedung Pane. Sebelum wawancara dimulai, partisipan diberi informasi tentang penelitian yang dijalankan dan diminta untuk menandatangani lembar persetujuan (consent form). Alat perekam dihidupkan dan diletakkan di depan partisipan setelah partisipan menyatakan siap untuk diwawancarai. Durasi wawancara untuk setiap partisipan sekitar satu jam dan diakhiri dengan debriefing.

\section{Analisis Data}

Transkrip yang didapatkan dari wawancara menjadi data mentah untuk dianalis is berdasarkan prosedur Interpretative Phenomenological Analysis (IPA). Perhatian utama saat menjalankan analisis data adalah interpretasi atau penafsiran terhadap pengalaman subjektif dari masing-masing partisipan. Interpretasi itu dijalankan sebagai interpretasi ganda (double-hermeneutic), yaitu peneliti "menginterpretasikan interpretasi" partisipan terhadap pengalamannya (Smith, Flowers, \& Larkin, 2009). Oleh karena itu, ada proses dinamis saat menjalankan penafsiran (Brocki \& Wearden, 2006). Tahapan analisis dimulai dengan mengambil transkrip dari satu partisipan dan membacanya berkali-kali dengan maksud mendapatkan gambaran menyeluruh tentang pengalaman partisipan. Peneliti kemudian membuat catatan-catan awal yang disajikan sebagai komentar eksploratoris terhadap transkrip. Catatancatatan awal itu selanjutnya ditransformasikan menjadi tema-tema emergen. Tema-tema emergen yang didapatkan kemudian ditransformasikan menjadi tema-tema superordinat yang menampung sejumlah tema emergen yang memiliki keterkaitan. Keseluruhan proses itu dijalankan secara terpisah untuk masingmasing partisipan. Setelah tema-tema superordinat dari seluruh partisipan didapatkan, peneliti kemudian melihat keterhubungan dari tema-tema superordinat itu.

\section{Kualitas Penelitian}

Untuk memeriksa kualitas penelitian kualitatif, ada beberapa kriteria yang bisa digunakan agar validitas bisa ditegakkan, seperti kriteria dari Ali dan Yusof (2011), Leung (2015) atau Yardley (2017). Dalam penelitian ini, validitas ditegakkan dengan menggunakan empat kriteria yang dikemukakan Yardley (2017), yaitu (1) sensitivitas pada konteks, (2) kelengkapan data, analisis, dan interpretasi, refleksivitas peneliti, dan (4) signifika nsi peneliti.

\section{HASIL DAN PEMBAHASAN}

Tujuan dari penelitian ini adalah mendapatkan jawaban untuk pertanyaan pokok penelitian, yaitu "Bagaimana narapidana pencabulan anak memaknai kasus 
hukum yang dijalaninya? Jawaban didapatkan dalam bentuk laporan pengalaman pribadi yang bersifat retrospektif, yaitu pengala man masa lalu yang dihadirkan kembali oleh partisipan sebagai orang yang mengalami langsung pencabulan pada anak. Saat menganalisis, peneliti bersandar sepenuhnya pada laporan partisipan. Hasil analisis menunjukkan empat tema superordinat, yaitu (1) kegagalan berdamai dengan keluarga korban, (2) kekecewaan pada keterungkapan kasus, (3) upaya luput dari tuntutan hukuman berat, dan (4) upaya menerima kenyataan. Berikut ini adalah gelaran temuan untuk empat tema superordinat itu. Saat menyajikan ekstrak dari transkrip, kami memperjelas konteks dengan menambahkan tiga notasi, yaitu "..." untuk jeda, "[...]" untuk bagian transkrip yang dihilangkan, dan "[keluarga partisipan] untuk penjelasan tambahan dari peneliti. Khusus untuk partisipan dengan pseudonim Subjek 2, penggunaan kata ganti "kita" perlu dimengerti sebagai "saya". Ini terkait dengan dialek di daerah tertentu di Kalimantan yang menjadi tempat asal Subjek 2.

\section{Karakteristik Partisipan}

Identitas semua partisipan disamarkan dengan menggunakan pseudonim untuk alasan etis, yaitu Subjek 1 dengan vonis 7 tahun, Subjek 2 dengan vonis 9,5 tahun, dan Subjek 3 dengan vonis 20 tahun. Seluruh partisipan dalam penelitian ini mendapatkan dukungan dari anggota keluarganya dan memiliki masa vonis yang berbeda-beda. Adapun masa vonis terlama ada pada subjek 3. Adapun karakteristik partisipan dapat dilihat pada Tabel 1.

Tabel 1.

Karakteristik Partisipan

\begin{tabular}{|c|c|c|c|}
\hline & Subjek 1 & Subjek 2 & Subjek 3 \\
\hline \multicolumn{4}{|l|}{ Usia } \\
\hline -pada saat kejadian & 24 tahun & 46 tahun & 20 tahun \\
\hline -pada saat wawancara & 30 tahun & 52 tahun & 27 tahun \\
\hline Usia Korban & 12 tahun & 17 tahun & 14 tahun \\
\hline $\begin{array}{l}\text { Status Korban } \\
\text { (teman/keluarga/tetangga } \\
\text { /lainnya) }\end{array}$ & Pacar & $\begin{array}{l}\text { Perempuan } \\
\text { pekerja di tempat } \\
\text { hiburan malam }\end{array}$ & $\begin{array}{l}\text { Perempuan } \\
\text { baru dikenal }\end{array}$ \\
\hline Vonis & 7 Tahun & 9,5 Tahun & 20 Tahun \\
\hline $\begin{array}{l}\text { Status pelaku } \\
\text { (menikah/tidak) }\end{array}$ & Belum menikah & Menikah & $\begin{array}{l}\text { Belum } \\
\text { menikah }\end{array}$ \\
\hline Pendidikan terakhir & SMA & SMA & SMP \\
\hline Dukungan keluarga & $\begin{array}{l}\text { Tersedia (Bapak } \\
\text { dan Ibu) }\end{array}$ & Tersedia (Istri) & $\begin{array}{l}\text { Tersedia } \\
\text { (Bapak dan } \\
\text { Ibu) }\end{array}$ \\
\hline Lama wawancara & 95 menit & 90 menit & 105 menit \\
\hline Pasal & $\begin{array}{l}\text { Pasal 81: Undang- } \\
\text { undang } \\
\text { Perlindungan Anak }\end{array}$ & $\begin{array}{l}\text { Pasal 81: } \\
\text { Undang-undang } \\
\text { Perlindungan } \\
\text { Anak }\end{array}$ & $\begin{array}{l}\text { Pasal } \\
\text { Undang- } \\
\text { undang } \\
\text { Perlindungan } \\
\text { Anak }\end{array}$ \\
\hline
\end{tabular}




\section{Kegagalan Berdamai dengan Keluarga Korban}

Ketiga partisipan harus mengikuti proses hukum setelah perbuatan cabul mereka dilaporkan ke kepolisian oleh keluarga. Anggota keluarga yang menjadi pelapor menjadi penentu apakah kasus dilanjutkan ke persidangan atau tidak. Salah satu alternatif yang bisa ditempuh oleh pelaku untuk menghindari persidangan adalah lewat jalur damai yang bisa dilakukan secara langsung dengan keluarga korban atau lewat bantuan oleh polisi. Semua partisipan telah mengupayakan jalur damai, namun berakhir dengan penolakan.

Subjek 1 mengemukakan keinginannya untuk bertanggung jawab menyekolahkan korban atau memelihara anak yang akan dilahirkannya. Dia bahkan meminta bantuan polisi untuk mendamaikan. Semua upayanya gagal karena penolakan oleh ayah dan ibu korban. Subjek 1 mengungkapkan:

\begin{abstract}
"Saya diminta pertanggungjawaban... Nah terus, saya sanggupi ... bapaknya yang menentang saya. Katanya saya gini, gini, gini, gini. Merusak anaknyalah, ini. Trus aku bilang gini, "Saya bertanggung jawab pak, saya sekolahkan lagi." Gitu. Anak saya, eng... apa namanya .. saya ... apa tuh namanya.. anaknya... anaknya saya bawa ke rumah. Saya yang ... bahasanya apa ya, ngopeni. He euh, tapi bapaknya gak mau .... Setelah itu, saya juga pake polisi. Pake polisi, terus pake pengacaranya. Pengacaranya, kalo bisa didamaikan di sini aja. Distop di sini. Tapi bapaknya sama ibunya gak mau, tetep gak mau. Anaknya kan sebenernya mau ... Setelah itu, terus diproses. Nah tiba-tiba saya dipanggil lagi. Dipanggil lagi, langsung ditangkep di situ, di tabes [kantor polisi] itu. Ditangkep, dimasukkan.
\end{abstract}

Ekstrak di atas menunjukkan dengan jelas bagaimana keinginan Subjek 1 untuk bertanggung jawab dan memelihara korban. Dia menyayangkan penolakan itu. Di bagian lain dari transkrip, terungkap secara implisit bahwa penolakan itu disebabkan oleh ketidakpercayaan keluarga akan kemampuan ekonomi Subjek 1 untuk memelihara korban:

[...] Bapaknya gak mau. Kamu kerja apa? Bilang gitu bapaknya. Ya saya ada pekerjaan, Pak. Saya kerja di perus ... eh gudang, gudang." Gajinya berapa?" gitu. Ya gaji gak usah ditanyakan to Pak, yang penting saya bisa menghidupi anak jenengan $[$ Anda].

Kejadian yang berbeda dialami oleh Subjek 2 yang diminta bertanggung jawab dengan menceraikan istri dan menikahi korban. Subjek 2 menolaknya dan memilih untuk menjalani hukuman:

Mamanya itu tetap keras waktu itu. Bapaknya itu sudah baik sama kita, diselesaikan secara kekeluargaan minta 60 juta. Bilangnya, katanya minta uang. Jadi sudah akur. Pabrik kita jual, pabrik padi ... Ternyata mamanya itu nggak mau. Bapaknya sudah mau, ibunya itu yang nggak mau... boleh bilangnya kalau kamu mau ceraikan istri kamu kawin sama anaknya boleh. Kita nggak mau. Kita bilang kita jalanin hukuman aja. Gitu aja itu aja Pak kesalahannya Pak.

Subjek 2 mengungkapkan bagaimana dia menjual aset usahanya untuk mendapatkan solusi damai lewat kompensasi finansial. Meski ada perbedaan sikap dalam keluarga korban tentang kompensasi, kesepakatan akhirnya adalah penolakan. Kompensasi finansial seperti itu juga menjadi solusi yang ditawarkan oleh Subjek 3 kepada keluarga korban. Tawaran itu juga menimbulkan perbedaan sikap dalam keluarga dan juga berakhir dengan penolakan.

Ya udah kita minta keluarganya mau damai gimana? Saya kiranya, mungkin karena bilang anaknya diperkosa, ya udah anaknya dinikahin aja. Tinggal pilihan anak bapak pilih yang mana, kita siap untuk menikahinya. Ya ternyata berbeda dengan pilihan kami. Keluarga mereka mengatakan, saya mau damai 
dengan satu syarat, saya harus mendapatkan uang 60 juta [...] Kita kumpulkan 60 juta. Yaudah daripada kita berurusan sama kepolisian ... Eh, di tengah perjalanan sebelum uang itu hampir keluar, ada satu keluarganya mungkin merasa malu karena kami mengundang keramaian warga di situ. Dan akhirnya malah dialah yang melaporkan kejadian ini ke kepolisian. Dan gak berselang lama akhirnya pihak kepolisian datang ke tempat kami. Dari situlah kami, loh pak kita udah deal loh pak, kita udah siapin 60 juta, kok kenapa kita masih dibawa ke jalur hukum?

Poin penting yang bisa ditarik dalam tema ini adalah bahwa penyelesaian masalah Prapersidangan bisa dilakukan lewat dua jalur damai, yaitu bertanggung jawab merawat korban dan memberi kompensasi finansial lewat keluarga. Cukup jelas dalam pernyataan seluruh partisipan bahwa kompensasi finansial tidak menjadi penentu dalam proses damai. Mereka berpandangan bahwa bila keluarga korban berada dalam penilaian sosial yang dipersepsikan sebagai tekanan, maka penyelesaian masalah melalui jalur hukum menjadi pilihan.

\section{Kekecewaan pada Keterungkapan Kasus}

Dari analisis transkrip, ketiga partisipan menerima bahwa perbuatan mereka salah, tetapi tidak menunjukkan penyesalan atas perbuatan itu. Upaya untuk berdamai telah ditempuh, tetapi semuanya gagal. Akibatnya, peristiwa pencabulan bergeser menjadi kasus pencabulan. Subjek 1 mengungkapkan kekecewaannya terhadap pergeseran itu:
"[...] tiba-tiba malah, di situ [keluarga korban] bawa polisi, keluarganya bawa polisi sendiri. Terus saya bilang gini, 'Lho Bu katanya kemarin gak ada polisi polisi?' Nah bilang gitu. 'Ya kamu kan sudah umur [berjarak usia yang jauh dengan korban],' gitu ibunya bilang gitu. 'Harus, kamu harus masuk [penjara]'.

Dalam potongan transkrip di atas, Subjek 1 mengungkapkan kekecewaannya pada penyelesaian lewat jalur hukum. Dia lalu berupaya menghindari persidangan, tetapi gagal. Saat menjalani persidangan, dia tetap mengupayakan hukuman yang lebih ringan. Saat mengetahui bahwa vonis yang diterima lebih berat daripada yang diharapkan, Subjek 1 menjadi sangat kecewa dan marah.

Yakaget [mendengarputusan]. Katanya
kan tiga tahun. Saya kan udah, ya
udahlah saya tiga tahun jalanin paling
berapa tahun lah, gitu. Dipikiran saya
kan gitu. Ternyata tiba-tiba tujuh tahun.
Waktu pulang itu aja, korsi yang itu, dari
luar kejak ... jaksa itu, apa, dari ruang
sidang itu, tak angkat, sempet mau tak
angkat. Tapi kan saya mikir ... yang
ngawal itu kan [saya] kenal.

Kekecewaan lain yang diekspresikan oleh partisipan adalah kejengkelan pada kecerobohan pribadinya yang berdampak pada pelaporan dan penangkapan. Dia merasa tidak bersalah dan tidak pantas untuk ditangkap. Jika ada kesalahan, maka kesalahan itu terletak pada lokus kejadian, bukan pada perbuatannya.

Waktu dulu minum itu.... minum.... habis minuman itu diajak ke tempat perempuan nakal itu [...] Kesel kita itu kalau kita nggak diajak ke rumah itu kemungkinan nggak papa. Yang kesalnya kita diajak ke rumahnya itu sampai kita ditangkap polisi tu. Kalau nggak diajak kita ke rumahnya tu kemungkinan kita nggak papa. Di situ cuman kesalahan kita itu kenapa kita ikut ke rumahnya itu. Ya itu ya kita merasakan gitu-gitu apakah kita ini dijebak atau nggak? [...] merasa kesal di dalam diri kita itu waktu itu. Mainnya udah di tempat lokasi itu kenapa kita diajak lagi ke rumah itu.

Dalam pernyataan itu, jelas bahwa Subjek 2 menilai perbuatannya bukan sebagai kesalahan. Istilah "nakal" yang disandangkan pada korban bisa dimengerti sebagai upaya membenarkan diri. Dia hanya menyayangkan tindakannya yang ceroboh karena berada di tempat yang salah saat melakukan 
perbuatannya pada korban. Dia menganggap dirinya "bodoh" karena mengambil keputusan dalam keadaan tidak sadar di bawah pengaruh alkohol.

[...] habis kita mabuk kita ikut ke
rumahnya. Habis ikut dia ke rumahnya
itu, kita kasi uang tiga ratus. Mau pulang
ada yang liat lho ada yang teriak...
Kalau kita itu waktu itu kita nggak
diajak ke rumahnya kemungkinan kita
nggak masuk lapas.

Rasa tidak bersalah juga ditunjukkan oleh Subjek 3 yang menganggap perbuatannya tidak membawa dampak yang buruk bagi korban. Dia membenarkan diri dengan menganggap korban tidak mempermasalahkan perbuatannya karena sudah dilakukan beberapa kali. Oleh karena itu, dia merasa sulit mengerti dengan tindakan korban yang berteriak histeris menyebut dirinya pemerkosa.

\section{Anehnya korban saya bahkan sudah kejadian dua kali, bahkan udah hampir tiga kali kok dia masih marah-marahdan seakan-akan kehilangan kesadaran. Dia mengatakan dia diperkosa [...] Lho kemarin sehari sudah kejadian, dua hari kejadian, dia gak pernah teriak-teriak kayak gini. Sekarang kok dia teriak- teriak dia diperkosa. Saya jadi kebingungan sama temen saya.}

Subjek 3 sulit menerima proses persidangan yang menghasilkan vonis dua puluh tahun untuknya. Dia merasa tidak adil dengan hukuman yang diterimanya. Dia mengungkapkan protes dan penolakan sembari membandingkan perbuatannya dengan kriminal-kriminal lain yang dinilain ya lebih buruk tetapi tidak menjalani hukuman.

Ini harusnya aku bebas. Aku harusnya, kenapa sih yang lain yang melakukan kejahatan yang memperkosa, yang merampok, mencuri, mereka masih berkeliaran di sana, tapi kenapa sedangkan saya yang baru seperti ini kenapa dimasukkan saya ke dalam penjara ini? Kenapa? Saya pertama kali menyalahkan Allah, memang saya menyalahkan itu. Kenapa harus saya yang dimasukkan ke sini? [...] Kenapa harus saya? Saya gak terima dengan kenyataan itu. Kenapa harus saya? Kenapa gak orang lain?

Pertanyaan pada diri sendiri yang diulang dan ditekankan menunjukkan bahwa hukuman yang dia terima adalah peristiwa yang dipandang tragis dalam hidupnya. Pertanyaan itu adalah pertanyaan eksistensial tentang ketidakadilan yang dia rasakan dalam hidupnya di mana Tuhan menjadi objek yang dianggap pantas untuk disalahkan.

Secara keseluruhan dapat dilihat bahwa ketiga partisipan tidak menampilkan rasa bersalah atas tindakan pencabulan mereka. Mereka menyayangkan peristiwa pencabulan yang bergeser menjadi kasus hukum. Dalam studi ini, kasus hukum yang mereka alami diatribusikan sebagai masalah eksternal yang disebabkan oleh penolakan keluarga dan masyarakat, bukan sebagai masalah internal yang bersumber dari kesalahan pribadi.

\section{Upaya Luput dari Hukuman Berat}

Dengan berjalannya kasus dalam proses persidangan, maka partisipan berhadapan dengan tuntutan hukum yang diproyeksikan berat. Di Indonesia, kasus pencabulan anak mendapat perhatian yang serius dari pemerintah dan diatur dalam peraturan pemerintah yang memberikan hukuman berat bagi pelaku. Dalam konteks ini, bisa dimengerti bila ketiga partisipan berupaya menemukan alasan yang bisa meluputkan mereka dari hukuman yang berat. Cara yang digunakan cukup bervariasi. Subjek 1, misalnya, menceritakan upayanya untuk bebas dengan meminta bantuan pengacara.

Sampe berapa kali sidang ya, dua belas kali. Selama sidang itu, terus berlanjut, berlanjut, terus, sampe pengacara saya, sebenernya bisa bebas, pengacara saya bisa jamin bebas. Nah akhirnya waktu pledo itu, pengacara saya meninggal. Ganti pengacara kan. Ganti pengacara, hakimnya bilang gini, ss...ss... sidang 
terakhir tu bilang gini, 'Mas, kamu tak kasih tiga tahun, terima ga?' 'Saya terima Pak.' Terus ternyata waktu sidang itu ada wartawan. Hakimnya kan terus ga berani kan ... Yaudah, kena tujuh tahun.

Berbeda dari Subjek 1 yang menggunakan jasa pengacara, Subjek 2 berada dalam kondisi sulit membela diri karena diketahui oleh orang banyak segera sesudah melakukan perbuatannya. Meski begitu, dia tetap berusaha untuk lolos. Dia menunjuk seseorang yang bisa dijadikan saksi bahwa perbuatannya bukan pencabulan, tetapi hubungan wajar antara pelanggan dan pelayan seks di lokasi tempat dia minum alkohol. Dia ingin meyakinkan polisi bahwa dia berada di rumah korban karena ajakan korban, tetapi usahanya itu sia-sia.

Waktu itu diinterogasi sama polisi itu kita bilang ... kita ambil di lokasi [tempat minum]. Dia kerjanya di situ waktu itu. Kalau kita waktu itu kita nggak mau diajak ke rumah, kita kemungkinan nggak ketangkap. Yang punya lokasi itu ada, kita panggil yang punya lokasi, yang kerja di situ. Yang punya lokasi itu bilang dia nggak di situ sedangkan dia di situ kerjanya ... Wong kita nggak ada ajak dia secara paksa nggak ada nggak ada secara paksa.

Pada partisipan Subjek 3, upaya luput dilakukan dengan berbohong dan mengingkari semua pertanyaan yang diajukan polisi saat penyidikan. Dia berhasil lepas untuk beberapa hari sampai akhirnya kembali dipanggil menjadi saksi. Saat polisi melakukan pemeriksaan, dia mengingkari semua pertanyaan penyidik dan kemudian mengakui setelah tiga pelaku lain menyebut keterlibatannya.

Saat kami di Polres, 3 orang udah mengakui ... saat itu saya masih mengelak ... saya masih membolakbalikan kata ... Semua penyidik saya bohongi .... Setelah empat hari dari polres mengatakan mohon saksi-saksi datang ke tempat polres. Nah saat itulah kami datang kembali ke sana .... Salah seorang teman saya yang di dalam polre s mengatakan, iya pak dia ikut iya pak dia ikut. Dan kejadian itulah yang membuat saya gak bisa mengelak apapun. Tadinya saya masih mengelak, saya enggak pak saya gak melakukan. Tapi ternyata temen saya datang dan mengatakan, iya pak dia ikut. Nah di saat itulah saya gak bisa mengelak, iya pak saya mengakui saya mengikuti.

Dapat disimpulkan bahwa tema ini menampilkan respons umum dari ketiga partisipan untuk berupaya bebas dari tuntutan melalui pembenaran diri dengan cara mengingkari atau berbohong. Secara umum, kondisi psikologis yang muncul saat gagal adalah rasa terpojok dan tidak puas.

\section{Upaya Menerima Kenyataan}

Masa tahanan yang dijalani ketiga partisipan dalam penelitian ini memiliki rentang antara 7 tahun 20 tahun. Rata-rata partisipan telah menjalani masa hukuman lebih dari 5 tahun. Di masa-masa awal menjadi warga lembaga pemasyarakatan, partisipan masih membawa macam-macam emosi yang terhubung dengan penolakan pada vonis, seperti yang diungkapkan dalam ekstrak berikut:

Subjek 1 : Kadang bayangkan ... kok bisa sampai di sini gitu.

Subjek 2 : Itu apa rasanya itu. Rumit. Rumitnya bukan main.

Subjek 3 : $[\ldots]$ merasa kosong semua. Udah pokoknya hidup tuh udah gak ada gunanya.

Dari waktu ke waktu, partisipan menjadi lebih tenang dan mulai bisa menerima. Subjek 1 bisa mengakui kesalahannya dan mengungkapkan keinginannya untuk mendapat kesempatan bertanggung jawab memelihara anak dari hubungannya dengan korban.

Ya gimana lagi. Kita kan salah. Kita kan udah ngelakuin, kasian lah, dia di bawah umur, hamil punya anak, kasian. Saya kan gini, prinsip saya kan gini, besok 
kalo keluar, kalo bisa saya, anaknya saya ambil, gitu. Atau masalah orang tuanya, pikir terakhirlah. Yang penting, anak sama...emangnya $\mathrm{mm}$ masih mau ga sama saya? Gitu.

Subjek 2 juga sudah menunjukkan penerimaan serupa. Ada harapan yang dia kembangkan tentang kehidupan keluarganya saat dia mengatakan:

Kalau kita keluar dari sini mudahmudahan kita hidupnya sepertidulu lagi sama anak kumpul-kumpul lagi. Waktu dulu kita masih ada ya kumpul sama anak sama istri. Kan istri kita nggak bisa kerja, di rumah aja, kita yang kerja jadi kita bisa buat warung ....

Bisa dimengerti bahwa kedua partisipan di atas mampu melihat ke depan dan mengembangkan harapan karena masa hukuman mereka yang dirasakan mendekati pembebasan. Ekspresi yang berbeda ditunjukkan oleh Subjek 3 yang masa hukumannya dirasakan masih sangat lama. Harapan ke depan tidak diekspresikan, tetapi lebih keadaannya lebih tenang akibat penguatan emosional yang didapatkan dari keluarga yang selama ini diasumsikan menolak dan menyalahkan.

Saya kaget di dalam sel dipanggil, "Hey, kunjungan". Loh, siapa yang kunjungan? "Keluargamu datang". Dan saat itu saat melihat keluarga saya, mereka meneteskan air mata. Ya Allah, rasanya saat itu rasanya kesedihan dalam hidup saya. Sangat sedih pokoknya, jatuh banget .... Keluarga saya bukan menghina saya, bukan menjelekjelekkan saya, tapi malah ayah dan ibu saya bilang, kamu yang sabar, iya bapak tahu kamu dihukum sendiri, tapi tenang aja, kamu kuat, kamu siap, kamu lakilaki, kamu harus siap menjalani apa pun resikonya.

Selanjutnya, Subjek 3 juga mengungkapkan penguatan lain yang dia dapatkan di lembaga pemasyarakatan, yaitu penguatan dari ajaran agama. Bila sebelumnya dia mempertanyakan keadilan Tuhan, maka ajaran agama yang dia terima di lembaga pemasyarakatan membawanya pada pemaknaan pribadi bahwa dia sedang menjalani hukuman di jalan Tuhan.

Saya mulai mengenal agama dari agama saya yang mengatakan, perjalanan hidup itu gak seperti yang kamu inginkan, apa yang kamu inginkan belum tentu yang terbaik buat kamu, apa yang kamu cerai ya belum tentu kamu itu yang jalan kamu itu yang membuat saya berarti jalan saya di tempatkan ke sini tuh, mungkin ini jalan terbaik buat saya. Seandainya saya masih di luar, saya yakin gak akan namanya saya berubah. Boro-boro untuk mendoakan keluarga, inget kepada keluarga, ataupun apa. Boro-boro untuk sholat ataupun ngaji. Itu gak ada sama sekali.

Tema yang keempat ini mengilustrasikan upaya ketiga partisipan untuk menjadi realistis dengan situasi hidup yang sedang mereka jalani di lembaga pemasyarakatan. Mereka pada akhirnya bisa menerima kenyataan bahwa mereka harus menjalani hukuman. Ada guncangan sesaat di masa awal penahanan. Dalam perjalanan waktu, mereka berusaha mengembangkan harapan yang positif tentang kehidupan keluarga.

Spice, Viljoen, Douglas, dan Hart (2015) berpendapat bahwa faktor determinan yang paling kuat dalam memunculkan perilaku pencabulan pada anak merupakan fiksasi dorongan seksual yang abnormal kepada anak, dan bukan pada orang dewasa. Dorongan ini bersifat internal, tidak sebagaimana perilaku kriminal lainnya, seperti mencuri yang didorong oleh faktor eksternal berupa masalah ekonomi. Pemenjaraan tidak serta merta mengalihkan fiksasi seksual seorang pelaku kekerasan seksual kepada anak, sehingga pemenjaraan bukanlah solusi untuk mengubah perilaku seksual abnormal yang dialami oleh pelaku kekerasan seksual pada anak (Mann, Hanson, \& Thornton, 2010). 
Pelaku kekerasan seksual pada anak menyadari bahwa fiksasi dorongan seksual yang dialami tidak dapat diubah, sehingga pelaku menganggap bahwa itulah cara dapat dilakukan dalam memenuhi dorongan seksual tersebut. Kondisi ini cenderung membuat pelaku kekerasan seksual untuk tidak menyesali perilakunya, sebaliknya, pelaku justru merasa malu dan kecewa dengan terungkapnya kasus tersebut. Pelaku merasa malu (shame) karena pandangan masyarakat yang buruk (perceived control behavior) dan kecewa karena dengan terungkapnya kasus tersebut, maka mereka tidak dapat kembali memenuhi dorongan seksual yang mereka miliki. Kemunculan rasa malu dan kecewa ini memang menekan perilaku seksual bagi para pelaku kejahatan seksual pada anak, namun keadaan ini tidak berlangsung lama (Spice dkk., 2015). Tangney, Stuewig, dan Hafez (2011) berpendapat bahwa pelaku kejahatan seksual yang hanya merasa malu (shame) dan kecewa tanpa adanya penyesalan (guilt) terhadap pengungkapan kasus percabulan yang dilakukan cenderung mengulangi perilaku yang sama pada saat mereka dibebaskan (menjadi residivis). Lebih lanjut, pelaku kekerasan seksual pada anak memiliki cognitive error yang lebih tinggi dibandingkan dengan populasi normal, di mana pelaku cenderung mengalami distorsi terhadap informasi-informasi yang benar namun berlawanan dengan keyakinan (belief) mereka (Kramer \& Drapeau, 2009). Hal ini didorong pula oleh impulsivitas yang tinggi, sehingga mereka berusaha menjustifikasi perilaku yang diperbuat walaupun bertentangan dengan moralitas yang berlaku (Schiffer \& Vonlaufen, 2010). Leigey (2010) dalam reviunya mengungkapkan, warga binaan yang menjalani vonisnya mengalami masa transisi di mana masa ini menimbulkan perasaan marah dan keinginan balas dendam yang cukup intens. Meskipun demikian, warga binaan yang mampu beradaptasi, menerima situasi pemenjaraannya akan menunjukkan lebih sedikit masalah kesehatan mental dan gangguan perilaku.
Penerimaan (acceptance) merupakan salah satu determinan dari timbulnya dampak negatif pemenjaraan. Leigey (2010) mengungkapkan bahwa self-acceptance memungkinkan pelaku kriminal untuk lebih menjaga kesehatan mentalnya, dibandingkan dengan pelaku yang justru self-blaming. Di sisi lain, dukungan sosial dalam penjara dan proses rehabilitasi sosial yang baik dalam penjara juga memainkan peranan yang penting bagi kesehatan mental tahanan (McKay, Comfort, Grove, Bir, \& Lindquist, 2018). Selain itu, bagi tahanan yang tidak mampu dalam menerima dan bahkan menolak realitas penahanannya, maka risiko timbuln ya masalah emosi negatif tadi bahkan muncul dan berdampak lebih lanjut kepada perilaku menyakiti diri dan bunuh diri (Butler, Young, Kinner, \& Broschmann, 2018).

Secara umum, tahanan akan mengalami berbagai cara untuk beradaptasi dalam kondisi sulit ini. Lembaga pemasyarakatan (lapas) secara umum sudah memberikan pembinaan yang komprehensif untuk merestorasi warga binaan agar siap untuk dimasyarakatkan. Sejumlah kegiatan ini berguna bagi warga binaan untuk dapat menurunkan emosi negatif yang dirasakan bila hanya berada di dalam sel tahanan. Di sisi lain, van den Berg, Beijersbergen, Nieuwbeerta, dan Dirkzwager (2017) mendapati bahwa para pelaku kekerasan seksual lebih merasa terisolasi, sulit bersosial, dan beradaptasi di dalam penjara. Hal ini membuat para pelaku kekerasan seksual di dalam penjara memiliki tendensi distres psikologis yang lebih tinggi.

Kecenderungan mengisolasi diri di dalam penjara di kalangan pelaku kekerasan seksual membuat mereka memiliki coping yang berbeda dalam mengatasi situasi sulit ini. Coping yang paling umum dilakukan secara individual di dalam penjara adalah coping religius atau spiritual yang dilakukan di dalam aktivitas keagamaan (Talik \& Skowroński, 2018). Lebih lanjut, coping religius atau spiritual memungkinkan tahanan merasa lebih tenang dan meningkatkan qulity of life serta 
dapat menurunkan distres psikologis, kecemasan, hingga suicidal ideation (Francis dkk., 2019). Namun, coping jenis ini tidak cukup untuk merestorasi kesehatan mental pelaku kekerasan seksual, di mana dukungan sosial harus tetap diusahakan guna menurunkan kecenderungan pelaku kekerasan seksual untuk mengisolasi diri di dalam penjara. Tanpa adanya keterampilan beradaptasi secara sosial, kemungkinan pelaku kejahatan seksual pada anak untuk mengulang kejahatannya sangatlah tinggi, karena para pelaku biasanya akan lebih mudah melakukan penetrasi sosial kepada anak-anak dibandingkan orang dewasa (Kras, 2018).

\section{SIMPULAN}

Penelitian ini mengungkap pengala man pelaku pencabulan anak dalam memaknai vonisnya. Hasil penelitian memunculkan empat tema superordinat, yaitu: (1) kegagalan berdamai dengan keluarga korban, (2) kekecewaan pada keterungkapan kasus, (3) upaya luput dari hukum berat, dan (4) upaya menerima vonis. Temuan penelitian ini menunjukkan pentingnya mencari strategi yang lebih efektif untuk membantu narapidana memahami dampak dari perilakunya. Pemahaman terhadap dampak perilaku menjadi penting untuk mencegah perilaku pencabulan anak diulangi kembali di masa yang akan datang. Penelitian selanjutnya dapat menggunakan temuan penelitian ini sebagai dasar pengembangan program rehabilitasi serta menguji efektivitasnya.

\section{UCAPAN TERIMA KASIH}

Penelitian ini dibiayai oleh Hibah Riset Pengembangan dan Penerapan sumber dana selain APBN UNDIP Tahun Anggaran 2018 (385-45/UN-7-P4.3/PP/2018). Terima kasih kepada Lembaga Penelitian dan Pengabdian Masyarakat UNDIP, dan asisten peneliti Valentino Marcel Tahamata, S.Psi

\section{DAFTAR PUSTAKA}

Ali, A. M. \& Yusof, H. (2011). Quality in qualitative studies: The case of validity, reliability and generalizability. Issues in Social and Environmental Accounting, 5(1), 2564. doi: 10.22164/isea.v5il.59

Baćak, V., Andersen, L. H., \& Schnittker, J. (2018). The effect of timing of incarceration on mental health: evidence from a natural experiment. Social Forces. doi:10.1093/sf/soy102

Brocki, J. M., \& Wearden, A. J. (2006). A critical evaluation of the use of interpretative phenomenological analysis (IPA) in health psychology. Psychology and Health, 21(1), 87-108. doi: https://oi.org/10.1080/14768320500 230185

Butler, A., Young, J. T., Kinner, S. A., \& Broschmann, R. (2018). Self-harm and suicidal behaviour among incarcerated adults in the Australian Capital Territory. Health Justice, 6(13), 1-6.

Cohen, L. J., \& Galynker, I. (2009). Psychopathology and personality traits of pedophiles. Psychiatric Times, 26(6).

Fazel, S., Hayes, A. J., Bartellas, K., Clerici, M., \& Trestman, R. (2016). Mental health of prisoners: Prevalence, adverse outcomes, and interventions. The Lancet Psychiatry, 3(9), 871881. doi: $10.1016 / \mathrm{s} 2215-$ 0366(16)30142-0

Francis, B., Gill, J., Yit Han, N., Petrus, C., Azhar, F., Ahmad Sabki, Z., ... Sulaiman, A. (2019). Religious coping, religiosity, depression and anxiety among medical students in a 
multi-religious setting. International Journal of Environmental Research and Public Health, 16(2), 259. doi: 10.3390/ijerph16020259

Ginneken, E. F., \& Hayes, D. (2016). 'Just' punishment? Offenders' views on the meaning and severity of punishment. Criminology and Criminal Justice, 17(1). doi: https:/doi.org/10.1177/17488958166 54204

Giorgi, A. (2009). The descriptive phenomenological method in psychology: A modified Husserlian approach. Pittsburgh: Duquesne University Press.

Komisi Perlindungan Anak Indonesia. (2018). KPAI ungkap jumlah kasus anak korban pelecehan seksual di sekolah. Diakses pada 13 Maret 2019, dari

http://www.kpai.go.id/berita/kpaiungkap-jumlah-kasus-anak-korbanpelecehan-seksual-di-sekolah

Kramer, U., \& Drapeau, M. (2009). The cognitive errors and coping patterns of child molesters as assessed by external observers: A pilot study. The Open Criminology Journal, 2(1), 24-28.

Kras, K. R. (2018). Can social support overcome the individual and structural challenges of being a sex offender? Assessing the social supportrecidivism link. International Journal of Offender Therapy and Comparative Criminology, 1-23.

La Kahija, Y. F. (2017). Penelitian fenomenologis: Jalan memahami pengalaman hidup. Yogyakarta: Penerbit Kanisius.

Leigey, M. (2010). Life without parole: A review of literature and directions for future research. Correction Compendium, 35(2), 247-268.
Leung, L. (2015). Validity, reliability, and generalizability in qualitative research. Journal Family Medicine Primer Care, 4(3). doi: 10.4103/2249-4863.161306

Matthews, B., \& Ross, L. (2010). Research methods: A practical guide for the social sciences. New York, NY: Pearson.

Mann, R. E., Hanson, R. K., \& Thornton, D. (2010). Assessing risk for sexual recidivism: Some proposals on the nature of psychologically meaningful risk factors. Sexual Abuse: A Journal of Research and Treatment, 22(2), 191-217.

McKay, T., Comfort, M., Grove, L., Bir, A., \& Lindquist, C. (2018). Whose punishment, whose crime? Understanding parenting and partnership in a time of mass incarceration. Journal of Offender Rehabilitation, 57(2), 69-82.

Schiffer, B., \& Vonlaufen, C. (2010). Executive dysfunctions in pedophilic and nonpedophilic child molesters. Journal of Sexual Medicine, 8(7), 1975-1984.

Smith, J. A., Flowers, P., \& Larkin, M. (2009). Interpretative phenomenological analysis: Theory, method and research. Los Angeles, CA: SAGE

Sinha, S. (2010). Adjustment and mental health problem in prisoners. Industrial Psychiatry Journal, 19(2), 101-104.

Spice, A., Viljoen, J. L., Douglas, K. S., \& Hart, S. D. (2015). Remorse, psychopathology, and psychopathy among adolescent offenders. Law and Human Behavior, 39(5), 451-462.

Suchy, Y., Whittaker, J. W., Strassberg, D. S., $\&$ Eastvold,

A. 
(2009). Neurocognitive differences between pedophilic and nonpedophilic child molesters. Journal of the International Neuropsychological Society, 15(2), 248.

doi: $10.1017 / \mathrm{s} 1355617709090353$

Talik, E., \& Skowroński, B. (2018). The sense of quality of life and religious strategies of coping with stress in prison inmates. Journal of Religion and Health, 57(3), 915-937.

Tangney, J. P., Stuewig, J., \& Hafez, L. (2011). Shame, guilt and remorse: Implications for offender populations. Journal of Forensic Psychiatry \& Psychology, 22(5), 706-723.

Tomar, S. (2013). The psychological effects of incarceration on inmates: Can we promote positive emotion in inmates. Delhi Psychiatry Journal, 16(1), 6672. van den Berg, C., Beijersbergen, K., Nieuwbeerta, P., \& Dirkzwager, A. (2017). Sex offenders in prison: Are they socially isolated? Sexual Abuse: A Journal of Research and Treatment, 30(7), 1-18.

van der Put, C., van Vugt, E. S., Stams, G. J. J. M., \& Hendriks, J. (2014). Psychosocial and developmental characteristics of female adolescents who have committed sexual offenses. Sexual Abuse, 26(4), 330342. doi:

https://doi.org/10.1177/10790632134 92342

Yardley, L. (2017). Demonstrating the validity of qualitative research. The Journal of Positive Psychology, 12(3), 295-296.

Yi, Y., Turney, K., \& Wildeman, C. (2016). Mental health among jail and prison inmates. American Journal of Men's Health, 11(4), 1-10. 